\title{
Many Roads to Modernization in the Middle East
}

\author{
Habibul Haque Khondker
}

Published online: 21 May 2011

(C) Springer Science+Business Media, LLC 2011

The classical Marxist view and the liberal view of Seymour Lipset, despite their many differences, shared a common view of the linkage between middle class formation and the push for democratization. The rise of middle class historically known as the bourgeoisie, a word etymologically connected to urban classes, was seen as the dreamers and carriers of democracy. The recent wave of prodemocracy movement in the Middle East and the North African (MENA) region was quickly seen by many as the unfolding of a much traveled historical trajectory. The waves of social revolutions in the MENA region beginning in Tunisia and then quickly spreading to Egypt were greeted in the Western media with applause. It was also seen by some quarters as a replay of anti-socialist uprisings of the 1980s and 1990s. As if the Tunis Spring followed by the Cairo Spring would spread in the region in the style of a domino. Contagion effect was in everybody's lips. Rebellions competed with metaphors. The days of autocracies in a turbulent region, were thought to be numbered. Then in March of 2011 as the Libyan uprising hogged the news channels, the tragic Japanese Tsunami rivaled for media attention. The metaphor of tsunami was quickly appropriated. Political tsunamis replaced the uprisings in the MENA region.

As revolutions spread from Tunisia to Egypt and Bahrain and spilling into Libya and Syria the air was getting heavier with a sense of doubt and trepidation. The crowded streets of Cairo and Benghazi had much in common but for Cairo

The data on quality of life are drawn from United Nations Development Program, Human Development Report, 2010.

H. H. Khondker $(\bowtie)$

Department of Humanities and Social Sciences, Zayed University, Abu Dhabi, United Arab Emirates

e-mail: Habib.khondker@gmail.com say a speech by the US president or some consultations at the highest level between the US and Egyptian leadership, or let us say, a nudge was enough. But when bombings of military targets and launching of Tomahawks are needed the spontaneous uprisings of the people become a matter of military engagement, popular rebellions escalate into wars with all the uncertainties associated with them. The dilemma of the US president Obama was a dilemma for all. Any war is always full of unintended consequences. Not intervening militarily in Libya would have been as difficult as defending sustained military engagement. Observers with fresh memories of Afghanistan and Iraq began to show some weariness and it is in that juncture, the discussion of diversity began to take the center stage.

In the euphoria of democratic uprisings and simplification of complex processes resulted in an oversight of historical time. The context for the velvet revolutions in the 1980s was the Cold War, when an economically stable America's tenacious and battle-ready sponsorship, unencumbered by the Gulf war was in a position to play an effective role. The US evoked not just awe for its military might but was a source of inspiration for its democratic ideals. The US at the time of MENA Spring was still reeling from an economic crisis, entangled and over-spent in multiple unpopular wars. The popular president having lost much of its charismatic appeal in the face of a revolution of rising expectation, exploited, if not orchestrated by the Tea Party and the assorted conservative forces in the United States. The US was not a force to reckon with in the early spring of 2011 followed by a legacy of bad memories of international misadventures which sapped its moral strength.

Also somewhat lost in the popular analysis was the divergence in the region. "Each case is different; all revolutions are local", wrote Simon Sebag Montefiore in the New York Times but only in late March. A common 
language and religion are strong forces of commonality but not stronger than the fission of politico-economic diversity. The diversity in the vision of leadership, the state capacity underpinned by the resource base of the government, the relationship between the rulers and the ruled, historical bases of legitimacy created significant diversities. The Tunisian dictator Mr. Zine El Abedine Ben Ali, like his Egyptian counterpart, Mr. Hosni Mubarak was perhaps little fatigued after decades of uninterrupted rule. Even if they did not want to leave, they lost the will to rule-sort of - and that's when the push came. People were tired of their rule as were they-tired of ruling. The uprisings eased their exit. Of course, there were scripted dramatic sequences of wanting to rule by force against the wishes of the people. The large number of unemployed, educated young men on the streets of Tunis or Alexandria or Cairo had nothing to lose except, perhaps, their chains of subjugation as the old Mao would have said. The downfall in some cases as in Egypt was foretold.

The historic spread of democratic uprisings that many were rooting for in the west may not come to materialize. The demographics, socio-economic contexts, and the political cultures are different. Looking from far, it often seems that the sandy region is rich in oil, despotic in rule and ready for democratic revolution. What is easily lost is the degree of diversity. The convergence of political trajectories has been overestimated. There, is however, a convergence in a common goal of modernization, a globalized modernization. Yet the paths to reach the shared goal are multiple as it has been the case in the attainment of modernization in other parts of the world starting with Europe. The push for creating a knowledge-based modern society with a sustainable and diverse economy became a shared goal of many of the countries in the region. The political economies are different, yet the technocratic aspirations converge.

The Arab Gulf region which is comprised of six states: Saudi Arabia, Bahrain, Kuwait, Qatar, Oman and the United Arab Emirates formed the Gulf Cooperation Council in 1981 are different from Iran as they are from Yemen. It is only in the development of international organizations, there is MENA (Middle East and North Africa) or the Arab World is made up of 21 countries some super rich, some dirt poor and many in between at different stages of economic growth. Some of the smaller but wealthier Gulf countries such as Qatar and the United Arab Emirates are paradigms of welfare states, providing an array of generous social welfare benefits covering health, housing, and education, even to marriage support.

Consider some of the countries of the Gulf Cooperation Council (GCC) such as the United Arab Emirates with its adult literacy (90\%) comparable to that of Asian tigers, life expectancy (77.7) following closely in the heels of that of the United States (79.6) or Britain (79.8) where many more women than men complete university education. A push for gender equality in higher education in the UAE entails creating space for male students. As a lecturer in an all women's university which in recent years has become coeducational with separate class rooms for the male students, I have witnessed some of these remarkable changes. A good number of female students come to school driving their own cars. Others are driven by female drivers drawn from the Philippines or parents who are keen on seeing their female wards partake in modern higher education. The students are armed with laptops, I-pads, connected to the wired world of the twenty-first century. This is a revolution of a different sort, a silent revolution. Yes, students come to class in the traditional garb, abaya, a flowing gown and cover their head but their minds are sufficiently open for them to interface with world of science and technology and cultural diversity. An Emirati student walked into the socalled male section of the Starbucks in Jeddah, Saudi Arabia unknowingly that the coffee-joint was gendersegregated. She was instantly shooed away into the female section - a veritable culture-shock for the Emirati woman of a new generation.

A silent revolution has been underway since the publication of the reports of the international organizations on the state of the play in the Arab world. The Arab Human Development Reports of the United Nations published in 2003 singled out knowledge-based economy as the central theme as it dwelt the gaps in Arab education. The reports in this series alerted the deficit in "knowledge, freedom and women's empowerment" in the region. The burst of interest in the Arab education and re-enlightenment followed in earnest in the new millennium and is sometimes perceived as a consequence of $9 / 11$. However, some of the changes began, including reforms in education, in the 1990s. The World Bank Development Report-The Road Not Traveled, 2008 which portrayed a dismal picture of the educational status of the Arab world was taken into account by the leadership of the region with seriousness it deserved. Different countries reacted differently to the report. In fact, in the GCC, a revolution of education and a race to be a part of the twenty-first century began in earnest in response to the report. New educational institutions blossomed in the region. Internet revolution caught the imagination of the young. A new space was created for those with rising expectations. The UAE has an internet penetration rate of $65.2 \%$ which competes favorably with that of East Asia's leaders such as Singapore's figure of $69.6 \%$. No wonder, the UAE looks to the East. Singapore comes up frequently in the discussion of development, technology. E-governance and digital infrastructures are discussed at ease with role of web-based education. 
However, some countries in the region, for example, the smaller Gulf countries had embarked on focusing on education and women's empowerment from the 1990s and others much earlier. The tiny Qatar took huge steps in attracting world class educational institutions. Offshore campuses of world class institutions predominantly from North America were invited to take part in the campaign of neo-enlightenment. It was different from "academic capitalism" a drive for providing much needed education and training for the development of human resources in the developing countries. This interest in world class education came from the top leaders who through the Qatar foundation invited a clutch of top-notch American universities starting with Virginia Commonwealth University's School of the Arts in 1998. The RAND Corporation was commissioned to study and then advice restructuring of the K-12 education system. The United Arab Emirates hosted the firstever off-shore campus of Sorbonne university and New York University in Abu Dhabi. Dubai had its share of offshore campuses of western universities driven both by commercial interests as well as academic excellence. Upgrading, accreditation, and excellence in education of local institutions became a common theme of the governments of the rich Gulf countries. Saudi Arabia was pursuing a drive for higher education for some time starting in mid 1970s mainly to meet the demands of human resource development in a growing hydro-carbon based economy. In 2008 a new university, King Abdullah University of Science and Technology (KAUST) dedicated to graduate training in science and technology with world-class aspiration was set-up. The first president of the university was hired from Singapore's prestigious National University of Singapore. The UAE too launched Masdar Institute of Science and Technology, an institution dedicated to research and graduate training in conjunction with world-renowned MIT in 2009. The new institute recruited 88 students in its first year from 22 countries and in 2010 the student population-only graduate students-rose to 100 who came from 25 countries.

The whole Gulf region is caught up with the creation of knowledge society in a hurry. This is an experiment of huge proportion. The launching of the MASDAR project, a carbon-free city in Abu Dhabi marked a giant step towards high-modernity. The young and aspiring health professionals in this dynamic city have their eyes fixed on Singapore and Korea for their field-trips.

The changes are not just limited to education and science; a growing number of Emiratis are being drawn to a culture of art and film festivals. Some students are big fans of Manga comics; others are listening to K-pop or developing a taste for Japanese food. Promotion of art and setting up of museums has become the priorities of the government. Here the interests of the state and the aspirations of the young converge. Maslow's name is often mentioned. There seems to be an aspiration for selfrealization-perhaps in artistic expressions.

The look east policy is often reflected in growing bonhomie between Singapore or South Korea and the UAE in diplomatic fronts and technological co-operations. The Gulf region is in the middle of a digital revolution. To jump into the conclusion that access to internet is a sure path to the world of liberal democracy may be misleading. Similarly, the conclusion that a liberal democracy is the only trajectory of modernization is also simplistic. Information revolution has brought East Asia close to the Middle East. In several East Asian countries starting with post-Meiji Japan, modernization has come from above, not below. In the Communist China change in the old-regime might have been initiated from below via a communist revolution, but modernization in the post-Mao era was imposed from above. Mr. Deng Xiaoping initiated economic and technological modernization with an eye to enhancing welfare of the population through various "modernizations" where democracy appears on the bottom of the list, not on the top. Consider Singapore, where the leadership's disillusionment with liberal democracy is shared by a large number of populace who are cognizant of both the value as well as the cost of western-styled liberal democracy. Singapore's remarkable economic growth and its success in creating a safe, stable society receive much attention in the Gulf. Although the discussions of the so-called illiberal democracy or democracy with an Arab character are yet to gain popularity in the cafes or seminars in the affluent part of the Gulf region, a tacit acceptance of the position that there are multiple roads to modernization seem to have gained grounds. A careful scan of the world will reveal that the path to modernity is not single but multiple.

\section{Further Reading}

Montefiore, S. S. 2011. Every revolution is revolutionary in its own way. The New York Times, March 26.

The World Bank. 2008. The road not traveled. The World Bank Development Report

Habibul Haque Khondker is a professor at Zayed University, Abu Dhabi, UAE. 